
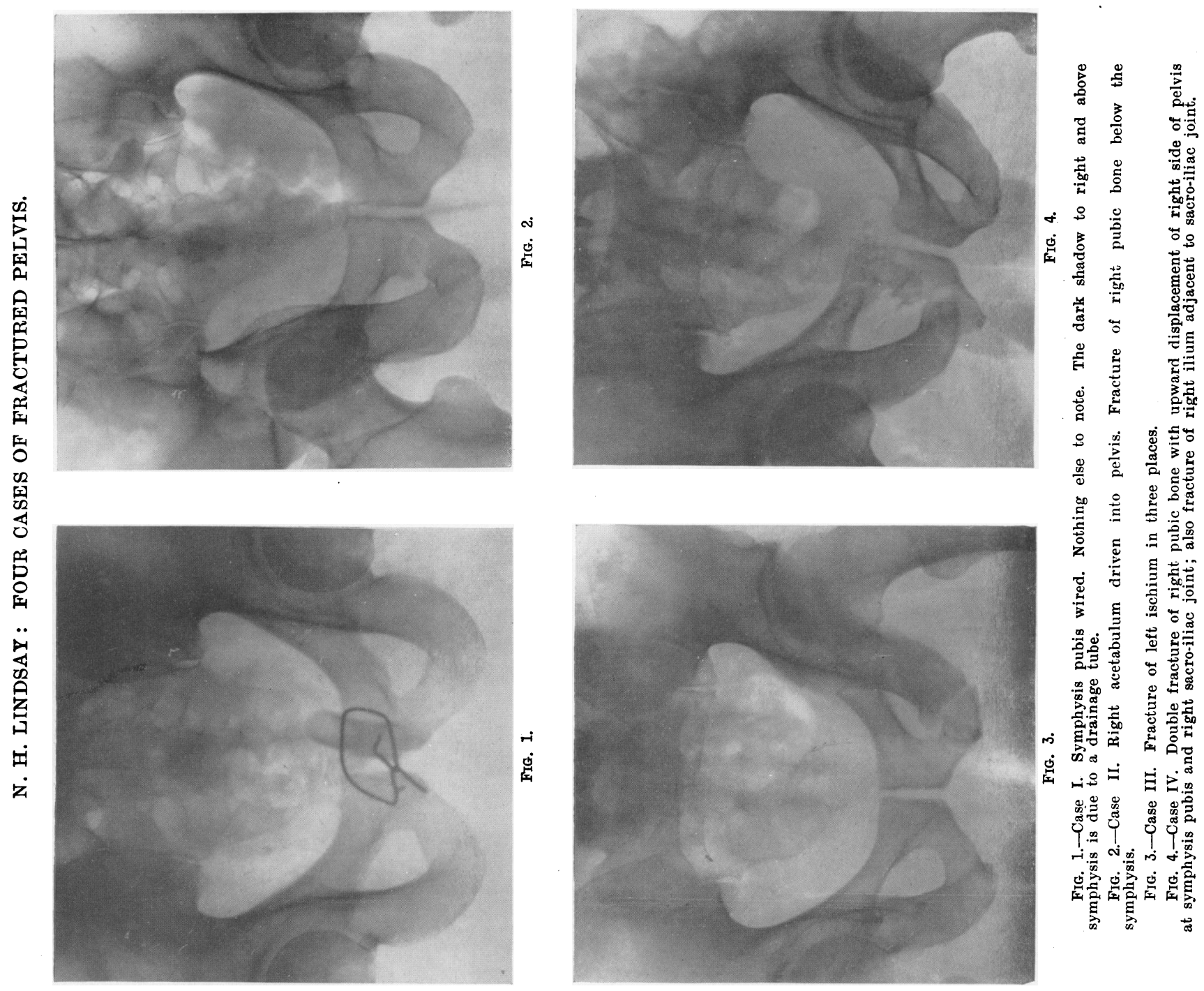

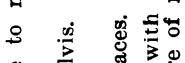

品

\&

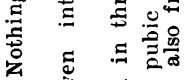

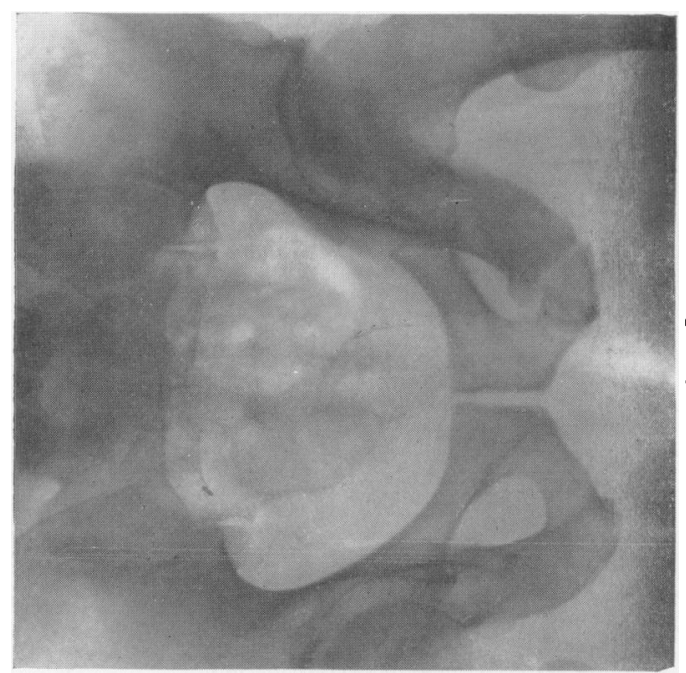

艺

离

品造过

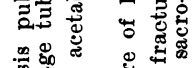

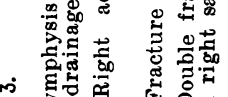

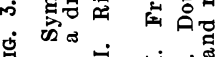
息 \%ँّ

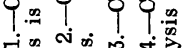

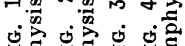

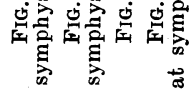
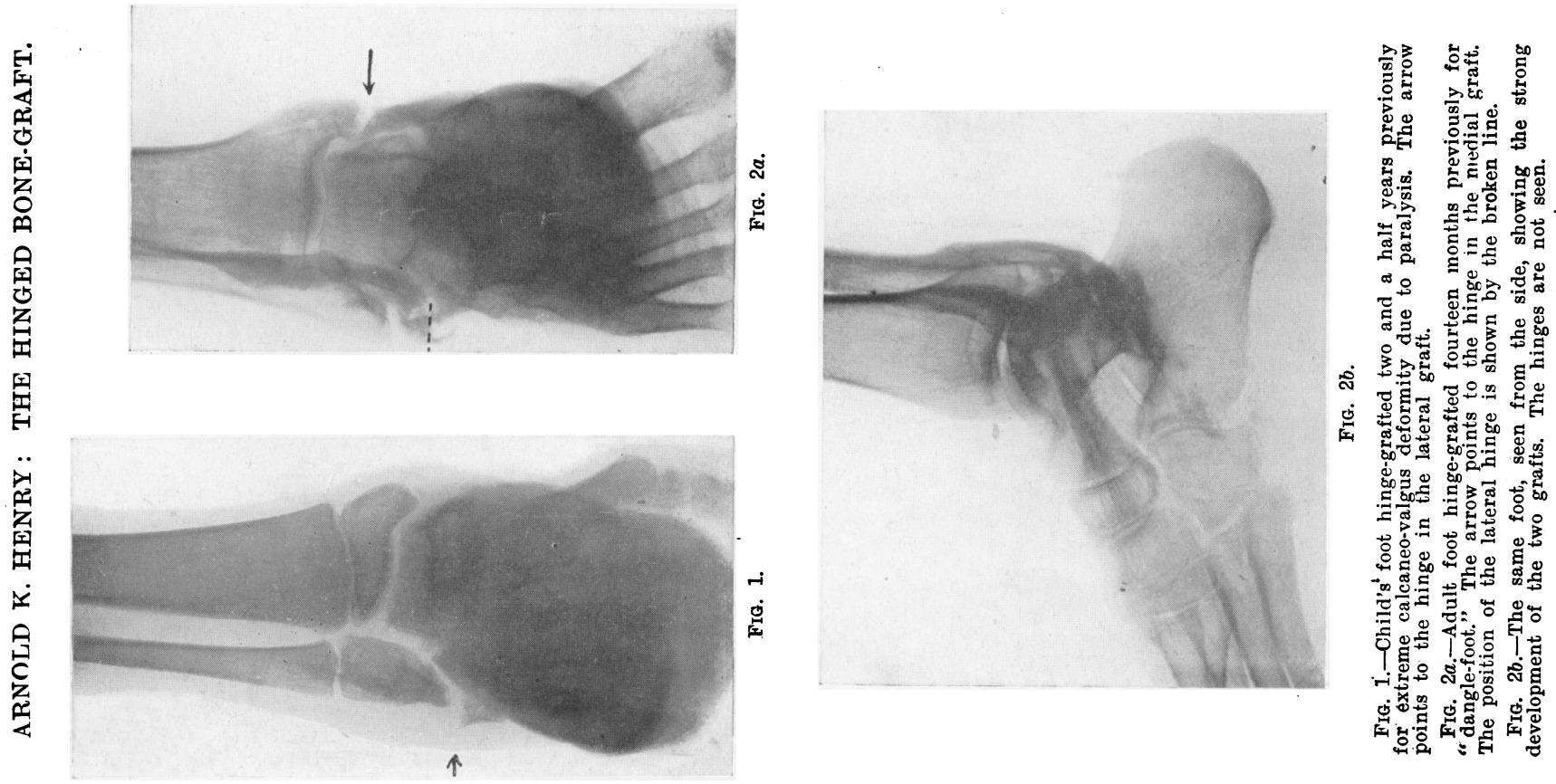
imperfect functional result," and "contraindicated in roung childien." The end-results, too, of tenodesis that I have seen have been riodinere, while other procedures are either mutilating or less simple of performance thim the operation of hinge-grafting.

Makers of artificial limbs realize the cisadrantage of a foot fixed immovably to the $\mathrm{lcg}$, and they provide limb. with a slight degree of movement at the ankle-joint. I believe that some mobility is equally desirable in the living foot, and that while bony fixation at right ankles to the leg is goorl, a stable foot with a few degrees of movement in the vertical plane is better. This can casily be got, in the most mintable feet, by means of hinged grafts.

rigs. $2 a$ and $2 b$ show $x$-ray pictures of a foot hingegrafted fourtecn months ago paralysed by a stab wound of the caula cquina. The foot is at a right angle to the leg, and the hinge grafts give a range of about 5 degrecs of movement in the vertical plane, which allows the leg to rock naturally on the foot when the patient walks. The rest of the limb is stabilize:l by means of a skelcton splint. It is particularly important in "dangle-foot" to bring the grafts across the midtarsal joint.

\section{The Operution.}

The following points are worth noting.

The P'osition of the Patient for Operation.-The frone position is best; this grives access to the backs of both mallcoli, and allows the graft to be cut from the opposite tibia after flexing the knee (Fig. 3 ).

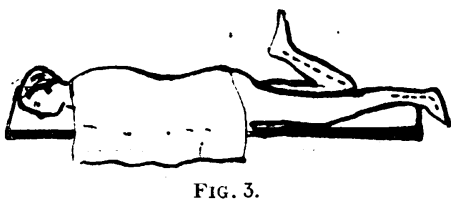

Slin Incision. - Time may be saved by making the thrce skin incisions-one extending to the foot from behind each mallcolus, anck one orer the opposite tibia-in succession at the beginning of the operation. The scalpel is then discarded, and a second scalpel is used for the deep dissections. Side-rurtains. are fixed to the neighbouring wounds behind the ankle by means of Michel clips, is aroid a double encumbrance of towel forcens.

The Graft 73ed.-Medially the tibialis posterior, and laterally the peronei, are displaced from their grooves, which are decpened by a gouge to form beds for the grafts; each groove must cross the mid-tarsal joint. The grafts are held in position by stitching the tendons over them; four stitrhes suffice for each graft. I do not permit either m own skin or the patient's to come in contact with the outer surface of my gloves. By this precaution I avoid the elaborate game of skill in which wound, graft, and satures are treated as untouchable, and time is saved.

The Grafts.-I I cut the ostro-periosteal strip, which is outlined by a salpel, with a chisel of the same width as

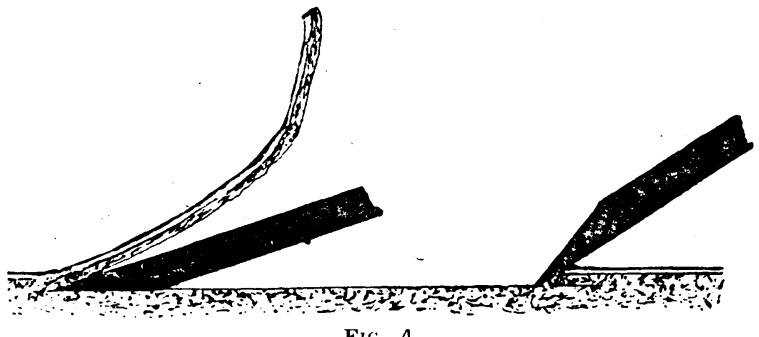

FIG. 4

the subcutaneous face of the tibia-entering the chiscl, bevel up, to the required deptl, and then using it, bevel down, to shave off the strip (see Fig. 4). Then, holding the strip with tissue forceps by the four corners, I divide it longitudinally with straight scissors into two equal guafts. It does not seem to matter whether the graft has the pliability of wet paper or the spring of a hazel twig; the result is the same-a hingo, just distal to the malleolus, is ultimately formed in either case. The patient whose radiogaph is shown in Fig. $2 a$, where the hinge is rearly scen, was grafted with tough, springy grafts, while in the girl's foot (Fig. 1) the grafts were flaceid.

Slin ('losure.-Time is arain saved, and contamination from skin is avoided by postponing the closure of all three wounds till the end of the operation. Michel clips ale used instead of sutures, since the clips provide no path for infection. Rutheriord Morison's invaluable thick laver of sterile boric powder is applied as a dressing.

\section{After-Treatment.}

The foot is bandaged for a week at right angles to tho leg in an ordinary soft bandare; this permits the small degree of movement that produces the hinge in each graft. The Michel clips are then removed and the bandage reapplied. If there is any tendency to foot-drop or laterial deriation, or if the patient is unlikely to co-operate by remaining in ber, the limb is fastened to a long har. splint, with the foot at right angles to the leg. A month after operation a plaster casing that extends above the knce replaces the bandage or the splint, and holds the foot in the same position. The patient is made to stanul beside his bed on the plaster casing for increasing periods of time. The casing is removed two months after the date of operation, and the patient is encouraged to waik.

The Adrantages of Hinge-Grefting.

1. The stability given by these bony hinge grafts improves with use; they do not stretch like tendons that are fixed or trinsplanted.

2. The after-treatment is simple: final and satisfactory function is obtained within three months-a time which compares favourably with the long period of care and re-education required after transplanting tendons.

3. If relevant muscles can still contract, the hinges allow: movements of dorsiflexion and plantar flexion.

4. Hinge-grafting does not-like astragalectony-disfigure the ankle.

5. It gives cxcellent results in " dangle-foot."

6. For talipes calcaneo-valgus it is the method of choice -not, I submit, another poor best among a disheartening array of forlorn hopes; but a thoroughly satisfactory treatment of the deformity.

REPERENCE.

${ }^{1}$ Henry, A. K. : British Medical Journal, April 9th, 1927, 1. 663.

\section{FOLR CASES OF FRACTURED PELVIS. BY}

\section{న. H. LINDSAY, M.B., B.CH., B.A.O.,} HOUSE-SURGEON, . ROYAL UNITED HOSPITAL, BATH. (ITith S'pecial Plate.)

THE interesting features about the following. cases are the manner in which the lesions were.produced, illustrating the different trpes of fracture caused by varying types of violence, and the fact that all four patients were admitted to hospital within a fortnight of each other.

\section{CASE I.}

T. D., a railway guard, aged 48 , was admitted to hespital on January 17t!, 1930, with a fracture through the symphysis pubis with rupture of the bladder. It was an incomplete fracture produced by compression violence. The patient fell from a staiion platform, and was caught between the platform and the rumning board of a moving train.

The following symptoms were exhibited. Extreme pain on compressing the iliac crests; inability to move the lower limbs without causing severe pain, but no evidence of nerve lesion; urgent desire for micturition; passage of a catheter withdrew a few drops of blood-stained urine.

The same day, after $x$-ray examination, the bladder was $c x$ plored and the pubic symphysis exposed. A iinear tear, a quarter. to half an inch in length, at the junction of the anterior surface of the neck of the bladder and urethra was found and closerl. The left supcrior ramis of the pubis was displaced downwards and backwards, being separated from the right superior ramus by about two inches. The displacement was corrected by manipulation and the fragments wired in position. A catheter was passed and tied in. Micturition was normal within forty-eight hours.

Further treatment consisted in the application of a stout pelic binder and nursing on fracture boards. 


\section{CASE II.}

R. M., a painter, aged 38, was admitted on January 28th, 1930, with a fracture through the floor of the acetabulum and right pubic bone. It was an incomplete fracture produced by compression violence. The patient fell from a ladder on to his right hip. When admitted he was suffering from shock and severe pain in the right hip and groin.

Examination showed that active movement of the right leg was possible but extremely painful. There was no tenderness on pressing the iliac crests together. The right leg was in a position of marked external rotation, full extension, and slight adduction. There was marked flattening over the right great trochanter and relaxation of the ilio-tibial tract, but no palpable abnormality. Shortening to the extent of one inch was prcsent. There was no sign of injury to pelvic organs or nerves.

\section{CASE III.}

$T$. C., a window-cleaner, aged $€ 0$, was admitted on January 24 th, 1930, with a fracture of the left ischial tuberosity. It was an incomplete pelvic fracture due to direct violence, and was produced by a fall on to the buttocks from an 18-foot ladder.

The lower limbs appeared normal in position and movements, but the latter caused pain in the region of the left sacro-iliac synchondrosis. Marked tenderness was present on pressing over the left sacro-iliac joint, and also per rectum in the region of the left ischial tuberosity. There was no sign of injury to the peliic viscera, vessels, or nerves.

\section{CASE IV}

B. W., collier, aged 42, was admitted on February 4th, 1930 with a fracture through the superior and inferior rami of the pubis on the right side and through the ilium on the same side, lateral to the sacro-iliac articulation; it was a complete fracture of the pelvic ring.

This patient was caught by his clothes in a revolving shaft, lifted in the air, and then violently dashed to the ground. On examination the right leg was held in a position of slight flexion and external rotation, with some flattening over the greater trochanter on that side. There was severe pain about the pelvis on moving the lower limbs, but no loss of function in the hipjoints. Compression of the iliac crests also caused severe pain, and slight crepitus could be elicited. Shortening of the right leg tip to one inch was present.

Treatment of the foregoing cases consisted in proper immobilization of the injured areas by the use of sandbags, where necessary, and tight binders. In Cases iii and iv extension was applied-in the former to both legs, in the latter to the right leg, counter-extension being maintained by raising the foot of the bed.

I am indebted to Mr. Fuller, Mr. Mumford, and Mr. Terry for permission to publish these cases.

\section{Atemoranda:}

\section{MEDICAL, SUṘGICAL, OBSTETRICAL.}

\section{CHLORETONE POISONING.}

A Recent paper by Professor J. J. van Loghem of Amsterdam $^{1}$ recalls to my memory the following case of chloretone poisoning which I met in my practice.

One morning about two years ago $I$ was called to attend a Dutch lady who had crossed the Channel the night before and had taken Mothersill's remedy against sea-sickness. Her only complaint was that she had to lie in bed, for when she got up she had a feeling of having lost her balance and was unable to walk straight; when she tried she had a sensation as though she was walking on glass. She had no sickness or any other gastric symptoms. On clinical examination I found dilated pupils, al the well-marked signs of cerebellar disturbance, and the gait typical of a vestibular affection. Owing to her nervous condition she had a rapid pulse, but otherwise there was no evidence that any system except the central nervous system was affected.

After she had rested in bed for about twenty-four hours she was completely restored to her normal health. The only treatment I gave her was to administer a sedative and an aperient.

There was no doubt in my mind that the patient's symptoms had been brought about by an overdose of chlore tone, which is the principal ingredient in Mothersill's remedr. I believe that 4 grains of chloretone are present in each powder. The dilatation of the pupils mav, I think, have been due to the action of the scopolamine, which, accordingr to Dannenberg, ${ }^{2}$ is present in Mothersill's remedr. Chloretone poisoning is rare. Dr. W. Essex Wynter.3 and Dr. Donald Core descriherl cases in 1913.

\footnotetext{
2 Zeit. t. Hals, Nase und Oliren Heilkunde, 1928-29, 22, 123.

3 Lancet May 17th 1913, p. 1375.
4 Ibid., Jlay 31 st, 1913, p. 1557 .
}

Two patients treated by the former showed signs of incoordination, vertigo, dullness of sensation, a sense of effort in movement, and mental confusion. The latter treated three patients in whom mental symptoms-incoherence of thought and speech passing to dullness and almost imbecility-supervened.

London, N.W.8.

Herman S. N. Mexko.

\section{AUTO-BLOOD-TRANSFUSION.}

Is his interesting article in the Journal of November 30th, 1929 (p. 1006), on auto-blood-transfusion in two cases of rupturcd tubal pregnancy, Mr. H. B. Butler mentions Burch's four personal cases of auto-transfusion, one of which was after splenectoniy, when much blood had been lost. The following case came under my observation while house-surgeon in the Gilasgow Royal Infirmary in 1925.

A young man, aged about 26 , who had been a patient on the medical side suffering from splenomegaly with anaemia, was brought to Mr. Kay's wards for splenectomy. The operation, performed under splanchnic anacsthesia and chloroform, was one of much difficulty owing to adhesions, as well as to the gueat size of the spleen.

I was instructed to stand by, scrubbed up as for assisting, and when the spleen was removed it was handed to me to invert over a beaker containing some sodium citrate solution. The shrinkage of the spleen as the blood ran out-about $1 \frac{1}{2}$ pints-was very marked. By the time it had ceased to lun a senior assistant hail the preparaticns ready for transfusing it back to the patient, while the surgeon finished closing the abdomen. The patient made an excellent recovery.

I am indebted to Mr. James Taylor, F.R.C.S.Ed., honorary surgeon, Glasgow Royal Infirmary, who performed the operation, for permision to record this case.

Tina Gr.iy, M.B., Ch.B.,

IIall Tutor in Surgers and Extra-Surgeon to the Out-Patient Department, Glasgow Royal Infirmary.

\section{HYPERPYREXIA IN MEASLES.}

THE following case of hyperpyrexia in the course of an attack of measles seems to me to be of more than usual interest.

On the morning of March 23rd I was called to see a child, 2 years old, suffering from measles. The rash was developing, and I noticed nothing urrusual about the attack. The following morning, however, the father asked me to come at once as he thought the child was in a.fit. I accompanied him to the house, and found the child in an apparently dying condition. Her skin had a pale slate colour; she had no convulsions and no rash. Every now and then she emitted a long-drawn sigh. When I took her temperature the mercury went up to $110^{\circ} \mathrm{F}$.; it might have gone higher, but that is the limit registered by my thermometer. I at once put the child in a tepid bath and rapidly cooled the water down, letting it get quite cold. The temperature soon came down to $101^{\circ} \mathbf{F}$, , and I then put the child back in her cot and covered her with a light blanket. The temperature remained under $102^{\circ} \mathrm{F}$., and she made an uninterrupted recovery. On the day following the attack of hyperpyrexia the rash appeared again, and a week after the date when I was first called in the temperature was normal and the child secmed well. There were no other complications throughout the illness.

Manchester.

F. Vimont Brown, M.D.Lond.

\section{Repurts of Sintrtips.}

-TRF ATMENT OF GHATAL PROLAPSE.

AT a meeting of the Section of Obstetrics and Gynaecology of the Royal Society of Mecticine on March 21st, with the president, Mr:. Arthur Giles, in the chair, Professor Fletcher Shaw read a paper on the treatment of genital prolapse.

Professor Shaw remarked that there was now general agreement that the uterus was held in position by the pelvic floor, and that prolapse of this organ, or of the vaginal walls, could only occur if the floor tissues were damaged or weakened. The rational treatment for prolapse, therefore, was to repair and strengthen them by colporrhaphy. Professor Shaw gave a short history of the operation, recalling the fact that Donald commenced to treat prolapse of the uterus in this wity in 1888, since when the operation had been almost the sole mothod of treatment of this condition in the Manchester school. As the result of inrestigating a series of cases treated from 